\title{
Crescimento, teor e composição do óleo essencial de melissa cultivada sob malhas fotoconversoras
}

\author{
Growth, content and composition of lemon balm essential oil cultivated under color shading nets
}

\author{
Renata da Silva Brant ${ }^{\mathrm{I}}$ José Eduardo Brasil Pereira Pinto ${ }^{\mathrm{II}}$ Louise Ferreira Rosa ${ }^{\mathrm{III}}$

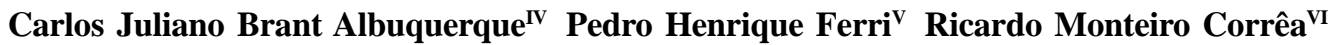

RESUMO

A utilização de malhas fotoconversoras para o cultivo de algumas espécies ornamentais e olerícolas tornouse comum. Diante da grande influência que a radiação solar exerce sobre os vegetais, esta pesquisa foi realizada com o objetivo de avaliar o efeito da intensidade e da qualidade espectral da luz transmitida pelas malhas fotoconversoras (Chromatinet $^{\circledR}$ ) em relação a aspectos fisiológicos de crescimento (teor, rendimento e composição química) do óleo essencial de Melissa officinalis L. Em delineamento inteiramente casualizado, foram dispostos quatro tratamentos e cinco repetições, sendo cada parcela composta de quatro vasos (uma planta por vaso). Os tratamentos foram caracterizados por plantas de melissa cultivadas a pleno sol, em malha preta $(50 \%)$, em malha Chromatinet ${ }^{\circledR}$ vermelha (50\%) e em Chromatinet ${ }^{\circledR}$ azul (50\%). As características avaliadas consistiram em: fitomassa seca de folhas, caules, parte aérea, raízes e total; razão raiz/parte aérea; área foliar total; razão de área foliar; razão de peso foliar; área foliar específica; teor, rendimento e composição química do óleo essencial. A utilização de malhas no cultivo de melissa favoreceu o crescimento, independentemente da cor, em relação ao cultivo a pleno sol. Sob a malha vermelha houve menores teor $e$ rendimento óleo essencial, porém apresentou o maior teor de citral.

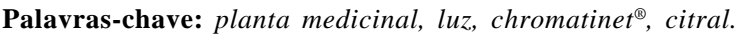

\section{ABSTRACT}

The use of color shading nets for cultivation of some ornamentals and vegetables has become common. Thus, observing the great influence of the solar radiation on the plant physiology, the objective of this research was to evaluate the the quantity and quality effects of spectral light transmitted through color shading nets (Chromatinet ${ }^{\circledR}$ ) in Melissa officinalis L., including physiological aspects as:growth, content and chemistry composition. Four treatments and five replications were disposed in a completely randomized design, being each experimental unit composed by four pots (one plant per pot). The treatments were lemon balm's plants cultivated under full sunshine, black shading net (50\%), red shading net (50\%) and blue shading net (50\%). The characteristics evaluated were: plant's height; dry phytomass of leaves, stems, aerial part, roots and total; root/aerial part ratio; total leaf area; leaf area ratio; leaf weight ratio; specific leaf area; content, yield and composition of the essential oil. The utilization of nets favored the growth organs dry phytomass yield, independently of the color, in comparison with total sun light. Plants under red shading had lower content of essential oil and yield, but they showed the higher content of citral.

Key words: medicinal plant, light, chromatinet ${ }^{\circledR}$, citral.

\section{INTRODUÇÃO}

Originária da região Sul da Europa, a melissa (Melissa officinalis L., Lamiaceae) também é conhecida pelos nomes populares de erva-cidreira, cidrilha e melitéia. É uma erva perene, de caule de secção quadrangular; folhas opostas ovais, verde-claras,

'Departamento de Agricultura, Universidade Estadual de Montes Claros (Unimontes), 39440-000, Janaúba, MG, Brasil. E-mail: renataplantasmedicinais@yahoo.com.br. Autor para correspondência.

"Departamento de Agricultura, Universidade Federal de Lavras (UFLA), Lavras, MG, Brasil.

IIIDepartamento de Agricultura, Universidade Estadual do Centro-Oeste (Unicentro), Guarapuava, PR, Brasil.

${ }^{\text {Iv } C e n t r o ~ T e c n o l o ́ g i c o ~ d o ~ N o r t e ~ d e ~ M i n a s ~ G e r a i s, ~ E m p r e s a ~ d e ~ P e s q u i s a ~ A g r o p e c u a ́ r i a ~ d e ~ M i n a s ~ G e r a i s ~(E p a m i g / C T N M), ~ N o v a ~}$

Porteirinha, MG, Brasil.

`'Departamento de Química, Universidade Federal de Goiás (UFG), Goiânia, GO, Brasil.

${ }^{\mathrm{V}}$ Centro Federal de Educação Tecnológica de Bambuí (CEFET), Bambuí, MG. Brasil. 
brilhantes e denteadas. As flores são esbranquiçadas, reunidas em glomérulos axilares. Possui odor semelhante ao do limão e é melífera. Os constituintes químicos principais são o tanino e o óleo essencial. A melissa é calmante, digestiva, carminativa, antiespasmódica e antinevrálgica. É usada para o tratamento de insônia, problemas nervosos e feridas e atua ainda como hipotensor. É aromatizante na culinária e em licores (MARTINS et al., 2000),

Em plantios comerciais, chega a produzir $1.800 \mathrm{~kg}$ de folhas secas ha- $\mathrm{ano}^{-1}$ (MARTINS et al., 2000), sendo o quilograma de folhas secas comercializado a R\$11,00(US\$6,50)(BLANKetal., 2005), e cada $10 \mathrm{~mL}$ do óleo essencial são comercializados a R $\$ 23,50$ (US\$13,90) (SUBHADRA, 2007), o que pode ser uma boa oportunidade para o produtor rural.

O desempenho das plantas em relação à energia solar incidente tem sido investigado há muito tempo. A partir disso, surgiram no mercado várias opções para oferecer proteção às plantas. Foram desenvolvidas algumas estruturas com telas, plásticos e vidros, originando os telados, as estufas e as casas de vegetação. De forma geral, os cultivos protegidos têm apresentado êxito para a produção comercial de algumas espécies. As malhas fotoconversoras Chromatinet da empresa Polysac Plastic Industries ${ }^{\circledR}$ são unidas mais densamente para atingir o mesmo efeito de sombreamento (50\%) e, de acordo com o fabricante, alteram o espectro de luz por elas transmitido. A malha azul transmite luz de uma banda larga em 470nm (azul), além de outros picos na região do vermelho distante e infravermelho (acima de 750nm), enquanto a malha vermelha possui uma maior transmitância em comprimentos de onda acima de 590nm (vermelho) e um pico menor em torno de 400nm (violeta), reduzindo ondas azuis, verdes e amarelas.

Pesquisas revelaram que plantas crescidas sob malhas vermelhas apresentaram maior comprimento das ramificações e, sob malhas azuis, apresentaram menor tamanho em relação à malha preta (neutra) (OREN-SHAMIR, 2001; SHAHAK et al., 2004). O cultivo da cenoura sobre coberturas amarelas promoveram maior teor de ß-caroteno e vitamina C. Isso indicou que a reflexão da luz pode ter ação direta no sistema de regulação do crescimento natural das plantas entre caules e raízes, como também pode influenciar o rendimento e a composição química de cenoura. (ANTONIOUS \& KASPERBAUER 2002),

No que concerne à fisiologia, os fitocromos ativam fatores transcricionais que induzem respostas das plantas à luz. Eles desempenham algumas funções nos vegetais, dentre as quais se destaca a capacidade de fornecer às plantas condições de detectarem o sombreamento por outras plantas. Nesse caso, a razão luz vermelha/vermelho-distante diminui, induzindo plantas de sombra a alocarem maior parte de seus recursos para o crescimento em altura; tal desempenho é conhecido como "resposta de evitação da sombra" (TAIZ \& ZEIGER, 2004).

A melissa parece ter bom desenvolvimento em meia sombra, porém sem excesso dessa condição. Assim, as informações disponíveis são apenas práticas (MARTINS et al., 2000), sem bases científicas, e não existem pesquisas referentes ao desempenho fisiológico dessa espécie quando submetida ao sombreamento e com espectros definidos. Além disso, por se tratar de tecnologia recente, existem poucos trabalhos nessa área, e os resultados obtidos com outras espécies não permitem estendê-los a outras.

Assim, observando a grande influência que a radiação solar exerce sobre a produção de fitomassa e de óleo essenciais, esta pesquisa foi realizada com o objetivo de avaliar o efeito da intensidade e da qualidade espectral da luz transmitida pelas malhas fotoconversoras (Chromatinet ${ }^{\circledR}$ ) no crescimento, no teor, no rendimento e na composição química do óleo essencial de Melissa officinalis L.

\section{MATERIAL E MÉTODOS}

O experimento foi desenvolvido no Município de Lavras, situado na região Sul do Estado de Minas Gerais, a 918,87 metros de altitude, latitude de $21^{\circ} 14^{\prime}$ 'S e longitude de $45^{\circ} 00^{\prime} \mathrm{W}$ GRW. De acordo com a classificação climática de Köppen, o clima regional é do tipo Cwa, mas apresenta características de Cwb, com duas estações bem definidas, uma fria e seca, de abril a setembro, e outra quente e úmida, de outubro a março (BRASIL, 1992).

As exsicatas estão depositadas no Herbário ESAL, do Departamento de Biologia da Universidade Federal de Lavras (UFLA), e correspondem ao n ${ }^{\circ} 22155$. As mudas de melissa foram produzidas a partir de uma planta matriz utilizando-se microestacas apicais de cinco centímetros de comprimento e dois milímetros de diâmetro e postas para enraizar em bandejas de poliestireno de 128 células, contendo o substrato comercial Plantmax $^{\circledR}$. Foram cultivadas em casa de vegetação com $60 \%$ de sombreamento e, posteriormente, aclimatizadas por meio do aumento gradativo da intensidade luminosa.

Os dados climatológicos da cidade de Lavras-MG foram fornecidos pela Estação Climatológica do Departamento de Engenharia Agrícola da UFLA, e as temperaturas médias locais em cada tratamento estão expostas na tabela 1. Em 
Tabela 1 - Dados climatológicos da cidade de Lavras, MG, no período de outubro de 2005 a março de 2006, e temperaturas médias locais em cada tratamento.

\begin{tabular}{|c|c|c|c|c|c|c|}
\hline Meses/Anos & $\mathrm{Tx}$ & $\mathrm{Tn}$ & Tméd. & Prec.total & UR. & Insol. \\
\hline Outubro/05 & 30,4 & 17,4 & 22,6 & 102,5 & 63,9 & 7,3 \\
\hline Novembro/05 & 26,8 & 17,0 & 20,9 & 191,2 & 77,8 & 4,8 \\
\hline Dezembro/05 & 27,4 & 16,9 & 21,2 & 257,3 & 77,5 & 5,0 \\
\hline Janeiro/06 & 29,4 & 18,3 & 23,0 & 149,9 & 70,5 & 7,3 \\
\hline Fevereiro/06 & 30,4 & 18,5 & 23,3 & 284,9 & 76,5 & 6,3 \\
\hline Março/06 & 29,3 & 18,0 & 22,4 & 281,5 & 79,2 & 6,9 \\
\hline Tratamentos & \multicolumn{6}{|c|}{ T méd. nos tratamentos } \\
\hline Pleno sol & \multicolumn{6}{|c|}{31} \\
\hline Preta & \multicolumn{6}{|c|}{27} \\
\hline Azul & \multicolumn{6}{|c|}{30} \\
\hline Vermelha & \multicolumn{6}{|c|}{28} \\
\hline
\end{tabular}

Tx- Média mensal da temperatura máxima $\left({ }^{\circ} \mathrm{C}\right)$.

Tn - Média mensal da temperatura mínima $\left({ }^{\circ} \mathrm{C}\right)$.

Tméd - Média mensal de Tx e Tn diárias $\left({ }^{\circ} \mathrm{C}\right)$.

Prec. total - Precipitação total mensal (mm).

UR - Umidade relativa do ar média mensal (\%).

Insol.- Insolação média mensal (horas).

dezembro de 2005, 80 mudas de $10 \mathrm{~cm}$ de altura foram transplantadas para vasos de $10 \mathrm{~L}$, contendo solo, areia e esterco bovino curtido (2:1:1). Os tratamentos foram caracterizados pelo cultivo das plantas sob disponibilidade de radiação solar incidente e qualidade espectral: pleno sol, malha preta com 50\%, malha Chromatinet ${ }^{\circledR}$ azul $50 \%$ e malha Chromatinet ${ }^{\circledR}$ vermelha $50 \%$, em cinco repetições, dispostos em delineamento inteiramente casualizado (DIC), sendo cada parcela composta de quatro vasos (uma planta/vaso). As malhas fotoconversoras utilizadas foram fornecidas pela empresa Polysac Plastic Industries ${ }^{\circledR}$. A irrigação foi realizada até o solo atingir a capacidade de campo, três vezes por semana.

As características de crescimento avaliadas foram: fitomassa seca de folhas (gramas planta ${ }^{-1}$ ), caules (gramas planta $^{-1}$ ), parte aérea (gramas planta ${ }^{-1}$ ), raízes (gramas planta $^{-1}$ ), fitomassa total (gramas planta ${ }^{-1}$ ), razão raiz/parte aérea $\left(\mathrm{g} \mathrm{g}^{-1}\right)$, área foliar total (AFT $\mathrm{dm}^{2}$ ), razão de peso foliar (RPF - $\mathrm{g} \mathrm{g}^{-1}$ ), razão de área foliar (RAF - dm $\mathrm{g}^{-1}$ ) e área foliar específica (AFE - dm² $\mathrm{g}^{-1}$ ). Após 13 semanas de cultivo, as plantas foram coletadas entre sete e oito horas da manhã. As folhas foram destacadas dos ramos e foi realizada a detecção da área foliar de quatro plantas representativas de cada tratamento, em $100 \%$ das folhas, por meio de um integralizador de área foliar MODEL LI-3100, Área Meter marca LICOR. Posteriormente, as folhas e os caules foram colocados em sacos de papel kraft e acondicionados em estufa de circulação forçada de ar a $35^{\circ} \mathrm{C}$, enquanto as raízes foram lavadas e, depois de retirada a umidade excessiva, foram também conduzidas à estufa. Depois de ter atingido peso constante, foram obtidas as massas dos materiais vegetais. A razão da área foliar (RAF), a razão de peso foliar (RPF) e a área foliar específica (AFE) foram determinadas a partir dos valores de área foliar total (AFT), expressos em $\mathrm{dm}^{2}$, da fitomassa seca da planta (P) e da fitomassa seca das folhas (Pt), expressos de acordo com BENINCASA (1988).

Para a extração dos óleos essenciais, as plantas sofreram uma triagem, selecionando-se apenas as folhas com bom aspecto visual. Foi utilizado o método de hidrodestilação em aparelho modificado de Clevenger. Dez gramas de folhas secas foram colocados em balão volumétrico de $1.000 \mathrm{~mL}$ e acrescentado um volume de $750 \mathrm{~mL}$ de água destilada.

Após a detecção de início de fervura, começou-se a cronometrar. Findo o período de extração de uma hora e meia, o hidrolato, obtido de cada hidrodestilação, foi submetido à partição líquido-líquido em funil de separação, com três porções de $25 \mathrm{~mL}$ de diclorometano (cada porção descansou por 20 minutos, totalizando 60 minutos por repetição). As frações orgânicas de cada repetição foram reunidas e secas com uma porção em excesso de sulfato de magnésio anidro. O sal foi removido por filtração simples, e o solvente evaporado, à temperatura ambiente, em capela de exaustão de gases até alcançar peso constante, obtendo-se o óleo essencial purificado.

Diante da massa obtida, determinou-se o teor percentual do óleo essencial nas folhas: $\mathrm{T} \%=$ massa do óleo (g)/10g x 100. O rendimento foi calculado pela fórmula: $\mathrm{R}$ = fitomassa seca total das folhas/planta (g) x massa do óleo obtido (g)/10g. 
As amostras foram identificadas por meio de cromatógrafo gasoso acoplado a um espectrômetro quadrupolar de massas CG-EM, Shimadzu QP5050A (Kyoto, Japão). Foram empregadas as seguintes condições: coluna CBP-5 (Shimadzu) preenchida em coluna capilar de sílica (30m comprimento x 0,25mm diâmetro interno x $0,25 \mu \mathrm{m}$ de espessura do filme, composto de fenilmetilpolisiloxano 5\%) conectada a detector quadrupólo operando em energia de impacto a $70 \mathrm{eV}$ com intervalo de massa entre $40-400 \mu$, com razão de 0,5 scans $\mathrm{s}^{-1}$; gás: He $\left(1 \mathrm{~mL} \mathrm{~s}^{-1}\right)$; injetor e temperatura de interface a $220^{\circ} \mathrm{C}$ e $240^{\circ} \mathrm{C}$, respectivamente, com razão de fluxo 1:20. O volume de injeção foi de $0,2 \mu \mathrm{L}\left(20 \%\right.$ em $\left.\mathrm{CH}_{2} \mathrm{Cl}_{2}\right)$ em fluxo e temperatura de $60^{\circ} \mathrm{C} \mathrm{e} 246^{\circ} \mathrm{C}$, com aumento de $3^{\circ} \mathrm{C} \mathrm{min}^{-1}$,

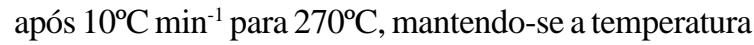
final por cinco minutos. A identificação dos constituintes foi realizada por comparação, automática e manual, dos espectros de massas obtidos com os das bibliotecas NIST/EPA/NHI (1998), por comparação dos espectros de massas e índices de retenção (IR) com os da literatura (ADAMS, 2001) e co-injeção com padrões autênticos. Os IR foram calculados a partir da co-injeção com uma mistura de hidrocarbonetos e C8C32 (Sigma, EUA) e com a aplicação da equação de VAN DEN DOOL \& KRATZ (1963). As concentrações relativas dos compostos foram calculadas a partir das áreas dos picos e expressas com valores aferidos nas três análises.

A análise estatística dos dados obtidos foi realizada pelo programa Sisvar ${ }^{\circledR}$ versão 4.3 (FERREIRA, 1999). As médias dos tratamentos foram submetidas à análise de variância pelo teste de F e teste de ScottKnott a 5\% de probabilidade de erro.

\section{RESULTADOS E DISCUSSÃO}

A produção vegetal da melissa foi afetada pelas condições de cultivo. Houve diferença para as características de fitomassa seca de folha, caule, parte aérea, raiz, total e área foliar (Tabela 2). Observou-se, entre as malhas, que o desempenho de crescimento foi semelhante; variando em relação ao cultivo a pleno sol. Diante disso, pode-se inferir que as plantas de melissa são insensíveis à qualidade de luz para produção de fitomassa e expansão foliar, sendo sensíveis apenas quanto à intensidade de luz, de forma que o sombreamento empregado pelas malhas (50\%), independente de sua cor, foi benéfico em relação às plantas cultivadas a pleno sol. LARCHER (2004) afirma que plantas crescidas sob forte radiação têm maior produção e um maior conteúdo energético de massa seca. No entanto, para melissa, esse conteúdo energético pode ter ficado alocado nas folhas sob forma de amido, sem que este fosse mobilizado para a produção de fitomassa. Esse desempenho pode variar entre as espécies. OREN-SHAMIR et al. (2001) verificaram maior percentual de ramos de maior comprimento e peso em plantas de Pittosporum variegatum sob malha vermelha em relação ao sombreamento com malha azul ou preta.

Ainda não está bem esclarecida a razão das alterações que ocorrem na alocação de fitomassa entre os órgãos da planta em resposta a alterações espectrais. Alguns estudos, no entanto, associam a percepção do sinal ambiental pelo fitocromo e pelos receptores de luz azul (criptocromos e fototropinas) e a resposta de crescimento de caules em Arabidopsis, atribuindo-lhes

Tabela 2 - Fitomassa seca das folhas, caules, parte aérea (PA), raiz e total (gramas.planta ${ }^{-1}$ ), área foliar total $\left(\right.$ AFT $=$ dm ${ }^{2}$ ), relação raiz/parte aérea (raiz/PA $\left.=\mathrm{g} \cdot \mathrm{g}^{-1}\right)$, razão de peso foliar $\left(\mathrm{RPF}=\mathrm{g} \mathrm{g}^{-1}\right)$, razão de área foliar $\left(\mathrm{RAF}=\mathrm{dm}^{2} \mathrm{~g}^{-1}\right)$, área foliar específica $\left(\mathrm{AFE}=\mathrm{dm}{ }^{2}\right.$ $\mathrm{g}^{-1}$ ), teor (\%) e rendimento de óleo essencial ( $\mathrm{g}_{\text {planta }}{ }^{-1}$ ) de Melissa officinalis L. cultivadas sob pleno sol, malha preta, malha azul e malha vermelha.

\begin{tabular}{|c|c|c|c|c|c|c|}
\hline Tratamentos & Pleno sol & Preta & Azul & Vermelha & Média Geral & $\mathrm{CV}(\%)$ \\
\hline Folha & $17,04 \mathrm{~b}$ & $20,06 a$ & $21,36 a$ & $22,12 a$ & 20,15 & 11,81 \\
\hline Caule & $11,16 b$ & $13,86 a$ & $15,60 \mathrm{a}$ & $15,18 a$ & 13,95 & 10,45 \\
\hline PA & $28,20 \mathrm{~b}$ & $33,92 a$ & $36,96 a$ & $37,30 a$ & 34,05 & 10,66 \\
\hline Raiz & $20,92 b$ & $28,74 a$ & $27,24 a$ & $28,18 a$ & 26,27 & 12,59 \\
\hline Total & $49,12 b$ & $62,66 a$ & $64,20 a$ & $65,48 a$ & 60,32 & 11,03 \\
\hline AFT & $36,92 b$ & $53,24 a$ & $54,24 a$ & $56,93 a$ & 50,33 & 9,96 \\
\hline Raiz/PA & $0,74 \mathrm{~b}$ & $0,85 a$ & $0,74 b$ & $0,75 b$ & 0,77 & 6,98 \\
\hline RPF & $0,35 \mathrm{a}$ & $0,32 \mathrm{a}$ & $0,33 a$ & $0,34 a$ & 0,33 & 4,75 \\
\hline RAF & $0,75 a$ & $0,85 a$ & $0,85 a$ & $0,87 a$ & 0,83 & 10,43 \\
\hline $\mathrm{AFE}$ & $2,17 a$ & $2,69 a$ & $2,56 a$ & $2,58 a$ & 2,50 & 13,55 \\
\hline Teor óleo essencial & $0,43 a$ & $0,44 a$ & $0,41 \mathrm{a}$ & $0,34 b$ & 0,40 & 14,13 \\
\hline Rendimento óleo essencial & $0,09 a$ & $0,09 a$ & $0,08 \mathrm{a}$ & $0,06 \mathrm{~b}$ & 0,082 & 15,15 \\
\hline
\end{tabular}

Médias na linha não seguidas pela mesma letra diferem entre si pelo teste de Scott-Knott a 5\% de probabilidade de erro.

Ciência Rural, v.39, n.5, ago, 2009. 
uma ação coordenada (PARKS et al., 2001). Segundo WEI\& DENG(1996) eCOLÓN-CARMONA et al.(2000), existe participação de genes, cujas ações mediadas por fotorreceptores modificam as relações entre reguladores de crescimento, alterando o balanço de auxinas, giberelinas e citocininas, em resposta a modificações espectrais, o que poderia modificar a distribuição de fotoassimilados. Desse modo, pode-se supor que plantas de melissa não respondem a esse mecanismo, nas condições desse experimento, pois não apresentaram respostas diferentes à incidência dos distintos espectros empregados.

Abordando a relação raiz/parte aérea, plantas sob malha preta apresentaram maior relação (Tabela 2). MARTINS (2006) empregou os mesmos tratamentos deste trabalho e concluiu que razão raiz/ parte aérea de Ocimum gratissimum L. (Lamiaceae) foi expressivamente maior a pleno sol, o que indica uma alocação preferencial de massa seca para o sistema radicular em comparação a plantas mantidas sob sombreamento. Esses resultados são contrastantes aos encontrados para melissa. Ou seja, para melissa, apenas a redução da intensidade luminosa fez com que houvesse maior alocação de assimilados para a raiz. Alterações espectrais não interferiram nessa variável.

Aumentos na RAF consistem na maior proporção de tecido fotossinteticamente ativo (PATTERSON 1980). No entanto, não foi detectada diferença entre os tratamentos. Já Dracaena marginata 'Colorama', cultivada sob malhas preta, azul, vermelha e cinza, apresentou maiores valores de RAF quando as plantas foram cultivadas sob malha vermelha (KAWABATA et al., 2007).

A RPF informa a eficiência produtiva do tratamento na produção de massa seca foliar em relação à massa da planta toda. Assim, para melissa, não foram encontradas diferenças (Tabela 2). Já plantas de Ocimum gratissimum (Lamiaceae) crescidas em ambiente de pleno sol e as sob malha azul apresentaram menores valores de RPF que as plantas sob malhas preta e vermelha. Isso demonstra que tratamentos sob pleno sol ou sob malha azul alocam menos fotoassimilados para as folhas em relação aos demais tratamentos. Valores de AFE foram mais reduzidos na condição de pleno sol, indicando que as folhas de $\boldsymbol{O}$. gratissimum tornam-se mais espessas quando as plantas são mantidas em local sem nenhum tipo de sombreamento (MARTINS, 2006). Esses resultados são distintos dos encontrados neste trabalho com melissa. A AFE relaciona um componente morfológico, a superfície da folha, com um componente anatômico, a fitomassa seca da folha (BENINCASA, 1988). Porém, não houve diferença nesta pesquisa. Já em estudo da palmeira-ráfia, com os mesmos tratamentos adotados nesta pesquisa, concluiu-se que não houve efeito dos diferentes tipos de malhas utilizadas para o cultivo no crescimento de mudas de Rhapis (MEIRELLES et al., 2007). Esses dados confirmam os encontrados com melissa.

Reportando-se aos óleos essenciais, as análises apontaram diferença entre os tratamentos e mostraram que, com o emprego do cultivo de melissa sob malha vermelha, o teor e o rendimento de óleo essencial foram menores. Os demais tratamentos não diferiram estatisticamente. Isso mostra que a intensidade de luz não interferiu na produção do óleo essencial e, sim, a qualidade de luz (Tabela 2). Portanto, as plantas de melissa não respondem positivamente à utilização da malha vermelha para a produção de óleo. Assim, é possível que a alteração no espectro incidente nas plantas, promovida pela malha vermelha, ocasione a falta de outro comprimento de luz (já que a malha possui filtro de transmissão de determinados espectros), que não absorvido pelos pigmentos, provoca a anulação de alguma rota importante para a síntese de terpenos e prejudica a produção do óleo essencial.

Em estudos com Mikania laevigata e Mikania glomerata (Asteraceae), foram utilizadas malhas vermelha, cinza e azul e pleno sol e concluiu-se que, para a primeira espécie, houve maior teor de óleo essencial sob malha vermelha e, para a segunda, sob malha azul. Para ambas, as plantas cultivadas a pleno sol apresentaram os menores valores (SOUZA, 2006).

Em Thymus vulgaris (Lamiaceae), a concentração total do óleo foi mais alta em plantas cultivadas a $100 \%$ de intensidade luminosa e diminuiu com o decréscimo no nível da intensidade. Dos 19 compostos comparados nos vários tratamentos de intensidade de luz, a maioria diminuiu com os decréscimos dos níveis de luz. O timol, composto majoritário, foi aproximadamente $10 \%$ mais alto em plantas submetidas a $100 \%$ de intensidade de luz do que a $27 \%$ (LI et al., 1996).

Referindo-se à qualidade do óleo, plantas cultivadas sob malha vermelha apresentaram maior quantidade de citral (neral + geranial), que é o composto majoritário e de maior interesse comercial em melissa. Resultados aproximados foram verificados entre os tratamentos malha azul e plantas cultivadas a pleno sol. O menor valor de citral no óleo essencial de plantas de melissa foi encontrado sob malha preta. Já o citronelal foi maior em plantas cultivadas sob malha vermelha e a pleno sol (Tabela 3).

As malhas fotoconversoras representam um conceito agrotecnológico novo, que objetiva combinar 
Tabela 3 - Composição química e percentagem relativa da área do óleo essencial de Melissa officinalis L. (\%) cultivada sob pleno sol, malha preta, malha azul e malha vermelha.

\begin{tabular}{|c|c|c|c|c|c|}
\hline IK & Compostos químicos & Pleno sol & Preta & Azul & Vermelha \\
\hline 1141 & desconhecido & 1,35 & 1,58 & 1,04 & 1,21 \\
\hline 1152 & citronelal & 0,76 & 0,10 & 0,10 & 1,61 \\
\hline 1193 & angelato de prenila & 2,84 & 3,59 & 3,62 & 3,31 \\
\hline 1240 & neral & 10,32 & 7,94 & 11,38 & 13,82 \\
\hline 1270 & geranial & 16,55 & 12,78 & 18,45 & 22,72 \\
\hline 1278 & epóxi-linalol (isômero desconhecido) & 20,90 & 26,82 & 19,89 & 18,45 \\
\hline 1283 & epóxi-linalol (isômero desconhecido) & 21,73 & 22,89 & 22,48 & 16,41 \\
\hline 1296 & desconhecido & 2,65 & 3,47 & 3,47 & 3,67 \\
\hline 1363 & acetato de nerila & 7,54 & 7,45 & 6,61 & 4,50 \\
\hline 1374 & trans-6-hidróxi-terpineol & 0,10 & 0,10 & 0,10 & 2,36 \\
\hline 1404 & desconhecido & 2,03 & 2,35 & 2,00 & 2,25 \\
\hline 1426 & desconhecido & 1,76 & 2,24 & 1,68 & 2,47 \\
\hline 1529 & desconhecido & 4,35 & 6,41 & 3,79 & 4,57 \\
\hline \multirow[t]{2}{*}{1585} & óxido de cariofileno & 4,38 & 2,49 & 2,24 & 2,64 \\
\hline & Total identificado & 85,12 & 84,16 & 84,87 & 85,82 \\
\hline
\end{tabular}

a proteção física, juntamente com a filtragem diferencial da radiação solar, para promover respostas fisiológicas desejáveis, reguladas pela luz. No entanto, para melissa, esse objetivo não foi atingido (SHAHAK et al., 2004).

\section{CONCLUSÕES}

De modo geral, a utilização de malhas no cultivo de melissa favoreceu o crescimento, independentemente da cor, em relação ao cultivo a pleno sol. Sob a malha vermelha, houve menor teor e rendimento de óleo essencial, porém apresentando o maior teor de citral.

\section{AGRADECIMENTOS}

Os autores agradecem ao Conselho Nacional de Desenvolvimento Científico e Tecnológico (CNPq) e à Fundação de Apoio à Pesquisa do Estado de Minas Gerais (FAPEMIG) pelo apoio financeiro e à Coordenadoria de Aperfeiçoamento de Pessoal de Nível Superior (CAPES) pela concessão de bolsa de estudos ao primeiro autor.

\section{REFERÊNCIAS}

ADAMS, R.P. Identification of essential oil components by gas chromatography/quadrupole mas sprestroscopy. Illinois: Allured Publishing Corporation, Carol Stream, 2001. 456p.

ANTONIOUS, G.F.; KASPERBAUER, M.J. Color of light reflected to leaves modifies nutrient of carrot roots. Crop Science, Madison, v.42, n.4, p.1211-1216, 2002.

BENINCASA, M.M.P. Análise de crescimento de plantas: noções básicas. Jaboticabal: UNESP/FCAV, 1988. 41p.
BLANK, A.F. et al. Produção de mudas, altura e intervalo de cortes de melissa. Horticultura Brasileira, Brasília, v.23, n.3, p.780-784, 2005.

BRASIL. Ministério da Agricultura e Reforma Agrária. Normas climatológicas de 1961- 1990. Brasília, 1992. 84p.

COLÓN-CARMONA, A. et al. Aux/IAA proteins are phosphorylatedby phytochrome in vitro. Plant Physiology, Minneapolis, v.124, n.3, p.1728-1738, 2000.

FERREIRA, D.F. SISVAR 4. 3-Sistema de analises estatísticas. Lavras: UFLA, 1999. (Software estatístico).

KAWABATA, A.F. et al. Effects of photoselective shade cloths on potted Dracaena deremensis 'Janet Craig' and Dracaena marginata 'Colorama'. Journal of Hawaiian and Pacific Agriculture, v.14, p.49-54, 2007.

LARCHER, W. Ecofisiologia vegetal. São Carlos: RiMA Artes e Textos, 2004. 531p.

LI, Y. et al. Effect of light on essential oil production of sage (Salvia officinalis) and thyme (Thymus vulgaris). Acta Hotrticultirae, Amsterdam, v.426, p.419-426, 1996.

MARTINS, E.R. et al. Plantas medicinais. Viçosa, MG: UFV, 2000. p.136-137.

MARTINS, J.R. Aspectos da germinação de sementes e influência da luz no desenvolvimento, anatomia e composição química do óleo essencial em Ocimum gratissimum L. 2006. 176f. Dissertação (Mestrado em Fisiologia Vegetal) - Universidade Federal de Lavras, Lavras, MG.

MEIRELLES, A.J.A. et al. Influência de diferentes sombreamentos e nutrição foliar no desenvolvimento de mudas de Palmeiras Ráfia Rhapis excelsa (Thunberg) Henry ex. Rehder. Ciência e Agrotecnologia, Lavras, v.31, n.6, p.1884-1887, 2007. 
NATIONAL INSTITUTE OF STANDARDS AND TECHNOLOGY. PC version of the NIST/EPA/NIH Mass Spectral Database. Gaithersburg, MD: U.S. Departament of Commerce, 1998. (Software de química).

OREN-SHAMIR, M. et al. Coloured shade nets can improve the yield and quality of Green decorative branches of Pittosporum variegatum. Journal of Horticultural Science and Biotechnology, Ashford, v.76, n.3, p.353-361, 2001.

PARKS, B.M. et al. Photocontrol of stem growth. Current Opinion Plant Biology, London, v.4, n.5, p.436-440, 2001. Disponível em: <http://www.sciencedirect.com/ science?_ob=ArticleURL\&_udi=B6VS4-444F51TD\&_user $=687358 \&$ \& rdoc $=1 \&$ \& $\mathrm{fmt}=$ \&_orig $=$ search \& _ s o r t $=$ d \& vi e w = c \&_ a c c t $=$ C $000037899 \&$ _ v e r s i o $n=1 \&$ u r l V e r s i o n $=0$ \&_u s e rid $=687358 \& m d 5=c 006433 c 9577$ c3585cc902f0be3e502b $>$. Doi: 10.1016/S1369-5266(00)00197-7.

PATTERSON, D.T. Light and temperature adaptation. In: HESKETH, J.D.; JONES, J.W. (Ed.). Predicting photosynthesis for ecosystems models. Boca Raton, Florida: CRC, 1980. p.205-235.

SHAHAK, Y. et al. ColorNets: crop protection and lightquality manipulation in one technology. Acta Horticulturae, Amsterdam, v.659, p.143-151, 2004.
SOUZA, G.S. Desenvolvimento vegetativo, características anatômicas e fitoquímicas de plantas jovens de duas espécies de guaco, submetidas a diferentes condições de qualidade de radiação. 2006. 117f. Tese (Doutorado em Fisiologia Vegetal) - Universidade Federal de Lavras, Lavras, MG.

SUBHADRA. Produtos: óleos essenciais. Capturado em 25 nov. 2007. Online. Disponível na Internet: http:// w w w . s u b had ra . c o m. br/e c o m/ p roduto s/ produtos.php?idc $=1 \& \min =20 \&$ counter $=10 \&$ pagina $=3$.

TAIZ, L.; ZEIGER, E. Fisiologia vegetal. 3.ed. Porto Alegre: Artmed, 2004. 719p.

VAN DEN DOOL, D.H.; KRATZ, P.D.J.A. Generalization of the retention index system including linear temperature programmed gas liquid partition chromatography. Journal of Chromatogrography, Amsterdam, v.11, p.463-471, 1963. Disponível em: <http://www.sciencedirect.com/ science?_ob=ArticleURL\&_udi=B6TG8-44R3XTC$14 \mathrm{P} \&$ _user $=687358 \& \_r d o c=1 \&$ fmt $=$ \&_orig $=$ search \&_sort $=\mathrm{d} \&$ $\mathrm{v}$ i e $\mathrm{w}=\mathrm{c} \&$ _ a c c t $=$ C $000037899 \&$ _ version $=1 \&$ \& r l V e r s i o $n=0 \&$ u s e r i d $=68$ 7358\&md5=7a6d255aac27fcc4ee209be9af4b8a88>. Doi: 10.1016/S0021-9673(01)80947-X.

WEI, N.; DENG, X.W. The role of the COP/DET/FUS genes in light control of Arabidopsis seedling development. Plant Fisiology, Minneapolis, v.112, n.3, p.871-878, 1996. 